\title{
Sambutan Novel Java Joe: Rahasia Kebangkitan Rara Jonggrang Karya J.H Setiawan terhadap Teks Babad Prambanan
}

\author{
Pipit Mugi Handayani \\ PBSI FPBS Universitas PGRI Semarang
}

\begin{abstract}
Abstrak
Kajian yang membandingkan antara sastra klasik dengan sastra modern yang menggunakan objek cerita Rara Jonggrang belum pernah dilakukan. Pada analisis ini kajian dibatasi pada pengaruh dan kesamaan antara teks Babad Prambanan dengan Novel Populer Java Joe: Rahasia Kebangkitan Rara Jonggrang. Kajian ini terfokus pada pengisahan cerita. Teks Babad Prambanan diposisikan sebagai teks yang lebih dahulu lahir sebagai karya sastra tulis dibanding dengan Novel Java Joe: rahasia Kebangkitan Rara Jonggrang yang lahir berikutnya dengan jarak waktu yang relatif jauh. Karya sastra tidak dapat dipisahkan dari pembaca sebagai penerima. Pada penelitian ini digunakan adalah resepsi sastra yang pada hakekatnya menempatkan pembaca sebagai subjek bagi sebuah karya sastra. Hasil penelitian ini dapat disimpulankan bahwa Novel Java Joe: Rahasia bangkitnya Rara Jonggrang merupakan tanggapan karya sebelumnya yang berupa babad dengan menghadirkan ide baru dan mempergunakan kreasi-kreasi berbalut science sebagai tampilan baru. Tanggapan tersebut merupakan penyangkalan cerita yang telah ada tentang cerita masa lampau sehingga esensi cerita yang ada tidak diabaikan. Perbedaan ide tersebut semata-mata adalah hasil pembacaan yang bertujuan memenuhi horizon harapan yang masih kosong pada karya sastra sebelumnya yang dijadikan sumber. Bisa jadi novel tersebut merupakan koreksi terhadap ide cerita pada karya sastra sebelumnya.
\end{abstract}

Kata Kunci: babad, sambutan, resepsi sastra, sastra banding.

\section{Abstract}

Studies comparing classical literatures to modern literatures that use the story of Rara Jonggrang as the object have never been done. In this analysis, the study is limited to the influences and similarities between Prambanan Chronicle text and popular novel Java Joe: The Secret of the Rise of Rara Jonggrang. This study focuses on storytelling. Prambanan Chronicle text is positioned as the first born literature in compare to Java Joe: The Secret of the Rise of Rara Jonggrang that is written subsequently in a relatively long time interval. The literature work cannot be separated from the readers as the receivers. In this study, literature reception, which essentially puts the readers as the subject of a literature work, is used. From the results of this study, it can be concluded that Java Joe: The Secret of the Rise of Rara Jonggrang novel is a response for the previous work which is in the form of a chronicle by presenting new ideas and creations wrapped using science as a new look. The response is a denial of the already existed story about the past stories so that the essence of the story is not overlooked. The differences in the idea are solely the result of reading that is aimed to meet the expectations horizon that is still vacant in the previous literature work used as the source. The novel could be a correction towards the ideas in the previous literary work.

Keywords: chronicle, reception, literature reception, comparative literature 


\section{Pendahuluan}

Karya sastra adalah salah satu unsur budaya. Sastra adalah hasil dari imajinasi seorang pengarang yang dituangkan dalam bentuk karya sastra yang bermediasi bahasa. Sementara bahasa sendiri adalah produk sosial. Karya sastra tidak akan tumbuh dengan sendirinya. Dia mengandung nilai yang sudah lebih dahulu ada dalam masyarakat. Karya sastra dapat diposisikan sebagai sarana masyarakat mengekspresikan ide dan maksudnya. Karya sastra tercipta untuk dibaca dan dimaknai.

Sebagai peneliti sastra, tugas peneliti bukan semata berkutat pada penelitian dan analisis terhadap karya sastra tidak hanya berpusat pada karya sastra modern saja akan tetapi juga pada karya sastra klasik. Salah satu karya sastra klasik di Indonesia yang perlu dipelajari dan dipahami isinya adalah babad. Dalam penelitian ini babad Prambanan sebelumnya telah diteliti dengan menggunakan objek kajian Babad Prambanan. Penelitian terhadap babad prambanan pernah dilakukan oleh Wening Udasmoro dan Heru Djarot Santoso dalam tesis mereka. Dalam penelitiannya yang berjudul Mitos Rara Jonggrang dalam Babad Prambanan dan Mitos Rara Mendut dalam Serat Pranacitra: Interpretasi dengan Strukturalisme Claude Levi-Strauss, Wening membandingkan cerita Rara Jonggrang dengan Cerita Rara Mendut menggunakan analisis strukturalisme Levi-Strauss yang membicarakan motif cerita kedua mitos tersebut.

Heru Djarot Santosa dalam tesisnya berjudul Babad Prambanan: Analisis resepsi meneliti Babad Prambanan dengan menggunakan analisis resepsi. Penelitian ini bertujuan menemukan resepsi antara cerita Rara Jonggrang dalam versi legenda dengan versi wayang. Sedangkan dalam penelitian ini, penulis membandingkan cerita Rara Jonggrang dalam bentuk babad dengan novel. Dengan demikian kajian yang membandingkan antara sastra klasik dengan sastra modern yang menggunakan objek cerita Rara Jonggrang belum pernah dilakukan.

Babad Prambanan merupakan salah satu karya sastra klasik yang lahir dalam bentuk tulisan. Analisis dibatasi pada pengaruh dan kesamaan antara teks Babad Prambanan dengan Novel Populer Java Joe: Rahasia Kebangkitan Rara Jonggrang. Kajian ini berfokus pada pengisahan cerita. Teks Babad Prambanan diposisikan sebagai teks yang lebih dahulu lahir sebagai karya sastra tulis dibanding dengan Novel Java Joe: rahasia Kebangkitan Rara Jonggrang yang lahir berikutnya dengan jarak waktu yang relatif jauh.

Dalam kajian ini diharapkan ditemukan 
resepsi dan makna dari pengaruh maupun kesamaan dari kedua objek kajian di atas.

\section{Landasan Teori}

Filologi adalah salah satu ilmu terapan yang mengkaji naskah dan teks masa lampau yang berupa tulisan (Baried, dkk. 1994: 1). Studi terhadap karya masa lampau dilakukan karena adanya anggapan bahwa dalam peninggalan tulisan terkandung nilai-nilai yang masih relevan dengan kehidupan masa kini. Kajian filologi menitikberatkan pada teks yang tersimpan dalam peninggalan tulisan masa lampau. Dalam pengertian Filologi sebagai studi teks merupakan salah satu studi yang dilakukan dalam rangka mengungkapkan hasil budaya yang tersimpan di dalam teks tersebut.

Karya tulis produk masa lampau, pada saat ini berada dalam kondisi yang tidak semua dapat terjangkau. Dalam hal bahasa dan kandungan teks, karya tulis masa lampau mengalami pergeseran konteks, yakni dari konteks penciptaan ke konteks pembacaan dari satu generasi masyarakat pembaca ke generasi masyarakat pembaca berikutnya (Chamamah, 2003:5). Tujuan utama mempelajari karya sastra klasik agar karya sastra tersebut "terbaca/dimengerti" , pada dasarnya ada dua hal yang harus dilakukan: menyajikan dan menafsirkan (Robson, 1994: 12).
Babad Prambanan sebagai salah satu karya sastra masa lampau merupakan representasi kehidupan pada masa lampau yang memiliki nilai moral yang masih relevan pada masa kini sebagai warisan budaya masa lampau. Berdasarkan tujuan umum filologi yakni mengungkapkan produk masa lampau melalui peninggalan tulisan dan mengungkapkan fungsi peninggalan tulisan pada masyarakat penerimanya, baik pada masa lampau maupun pada masa kini (Baried dkk. 1994: 7) maka studi filologi sangat tepat digunakan dalam analisis ini.

Secara umum tujuan kerja sastra banding menitikberatkan pada hubungan atau keterkaitan antara suatu karya sastra dengan karya sastra lain atau antara karya sastra dengan karya seni lain. Kajian sastra banding memiliki dua kajian yakni kesamaan (affinity) dan pengaruh (influnce). Kajian ini dilakukan untuk mengetahui adanya hubungan atau keterkaitan antara karya sastra yang dibandingkan. Terdapat empat asas yang menjadi pokok pembanding dalam kajian sastra bandingan yakni: pertama, genetik teks; kedua, generik teks; ketiga, tematik teks dan keempat, kesejajaran teks (Puji Santoso dalam Trisman. 2003: 106). Perbedaan dalam waktu penciptaan antara satu karya dengan karya lainnya tidak menjadi halangan untuk dibandingkan. Seseorang dapat saja membandingkan suatu 
manuskrip kuno dengan karya sastra yang bahkan baru diterbitkan asal saja kedua karya tersebut layak untuk ditelaah dan dibandingkan (Kasim, 1996: 21). Dengan demikian teks Babad Prambanan yang penciptaannya jauh sebelum novel Java Joe: Rahasia Kebangkitan Rara Jonggrang dapat pula dikaji menggunakan analisis sastra bandingan.

Selanjutnya dalam kajian ini digunakan kajian pengaruh yang dilaksanakan dengan langkah pertama yakni penelaahan dan penafsiran fenomena genetik (asal Usul) sebuah karya sastra, langkah kedua kajian yang bersifat tekstual dan komparatif yang berhubungan dengan persamaan-persamaan berdasarkan teks (Kasim, 1996: 45). Karya sastra tidak dapat dipisahkan dari pembaca sebagai penerima. Kajian resepsi sastra pada hakekatnya menempatkan pembaca sebagai subjek bagi sebuah karya sastra. Kajian resepsi sastra selalu terkait dengan sejarah sastra dimana peran serta pembaca tidak dapat diabaikan.

Hubungan karya sastra dan pembacanya memiliki dua implikasi yaitu estetika dan historis. Implikasi pertama, estetik, terletak pada fakta bahwa resepsi pertama terhadap karya sastra mengandung perbandingan antara nilai estetik karya itu dengan karyakarya yang pernah dibacanya. Sedangkan implikasi historis mengindikasikan bahwa pemahaman pembaca terhadap karya sastra akan diteruskan dan diperkaya dalam rangkaian resepsi dari generasi ke generasi (Jauss. 1996: 2) .

Berangkat dari pemikiran Jauss di atas dapat diuraikan bahwa hakikat dari resepsi adalah adanya horizon harapan seorang pembaca terhadap karya sastra. Karya sastra masih memiliki celah yang dapat diisi oleh pembaca yang merupakan masyarakat dari generasi ke generasi. Resepsi tersebut bergerak dari pemahaman pembaca dengan pengetahuan yang berbeda terhadap karya sastra pada masa lampau. Dengan demikian akan terjadi perbedaan persepsi terhadap karya sastra yang dibacanya. Sebagaimana pendapat Jauss pada tesis keempatnya:

The reconstruction of expectations, in the face which a work was created and received in the past, enables one on other hand to post questions that the text gave an answer to, ang thereby to discover how the contemporary reader could have viewed and understood the work. This approach corrects the mostly organized norms of a classicist or modernizing understanding of art, and avoids the circular recourse to a general "spirit the age" (Jauss, 1982:28).

Apresiasi pembaca terhadap karya-karya akan dilanjutkan dan diperkaya melalui tanggapan para pembacanya (Jauss via Pradopo, 2003: 209). Sebuah karya sastra 
bukanlah objek yang berdiri sendiri dan yang memberikan wajah yang sama kepada masing-masing pembaca di setiap periode (Pradopo, 2003: 209). Pada penilaian estetika tanggapan (resepsi) dapat dikenakan pada naskah-naskah tulisan tangan sastra lama amupaun sastra modern.

\section{Pembahasan}

\section{a. Babad Prambanan}

Babad adalah puisi kisahan berbahasa Jawa yang menyajikan rangkaian peristiwa sejarah Jawa; cerita pahlawan dalam peperangan (Panuti. 2006: 11). Babad merupakan karya sastra yang berisi hal-hal mengenai kerajaan, seperti silsilah keturunan raja, sejarah berdirinya kerajaan, moral keagamaan, adat istiadat, tuntunan cara kehidupan bermasyarakat dan bernegara, ataupun peristiwa-peristiwa penting lain yang terjadi dalam kerajaan. Oleh sebab itu dalam babad biasanya tertera angka tahun tiap peristiwa penting yang terjadi disertai hitungan sengkala. Sebagai contoh peristiwa hancurnya Kerajaan Prambanan yang terjadi pada tahun 1009 (cipta sonya ngambareku).

Berdasarkan penelitian melalui katalogus, naskah Babad Prambanan berjumlah sembilan naskah yang tersebar di berbagai tempat yakni tiga (3) buah di Perpustakaan Universitas Indonesia di Jakarta , satu (1) naskah di Perpustakaan
Nasional Republik Indonesia di Jakarta, satu (1) naskah di Keraton Yogyakarta, satu (1) naskah di Perpustakaan Museum Sanabudaya Yogyakarta, satu (1) naskah Di Museum Radya Pustaka Surakarta dan dua (2) naskah di Girardet Sebagian besar isi cerita pada naskah-naskah Babad prambanan tersebut merupakan wujud karya sastra yang berisi cerita tentang keberadaan dan kebesaran Prambanan.

Dalam hal ini teks babad prambanan yang digunakan dalam analisis ini adalah bentuk transliterasi dan ringkasan cerita dari naskah Babad Prambanan yang merupakan koleksi dari Perpustakaan Universitas Indonesia dengan kode naskah LS 3 NR 309. Teks Babad Prambanan ini sudah tersaji dalam dua bagian yang pertama dalam bahasa Indonesia sedangkan yang kedua dalam bahasa jawa krama. Teks ini berbentuk puisi yang berisi tembang macapat.

Pada bagian awal merupakan terjemahan dari bagian kedua yang berupa tembang macapat berjumlah 41 tembang. Yang masing-masing tembang terdiri dari 30-35 pada (bait). Seperti contoh sebagai berikut:

XIX. Asmaradana

1. Dasar us timurireki, Raden Bandung Bandawasa. Raden Bandung Bandawasa, nadyan endah ing warnane, tan arsa estri pideksa, dedege sariranya, kang kinarsan Raden Bandung, 
pawestri kang awak lanang.

2. Dedeg purisa mantesi, ayu sembada warnanya, pantes ing tandang tanduke, kang dadya karsaning priya, mangka mangke umiyat Rara Jonggrang warnanipun, ayu sembada ing warna.

3. Dedeg pideksa mantesi, dinangu matur prasaja, yen arinira sang katong, Karungkala kang eus lena, parap Dyah Rara Jonggrang, maksih lamban marmanipun, diwasa tas arsa krama (Sugiarti, 1981: 150).

Dialihbahasakan ke dalam bahasa Indonesia menjadi:

\section{Asmaradana}

Wajah dan tingkah laku Rara Jonggrang sangat menarik hati Raden Bandung Bandawasa. Ketika ditanyai oleh Raden Bandung Bandawasa, Rara Jonggrang menceritakan bahwa dirinya adalah adik dari Prabu Karungkala yang telah tewas dalam peperangan. Ia masih perawan dan tidak mau kawin (Sugiarti, 1981: 33).

Pada teks Babad Prambanan ini ditemukan cerita yang sangat panjang bukan hanya cerita tentang Rara Jonggrang saja melainkan cerita penting lain tekait dengan asal usul kerajaan di Jawa. Cerita-cerita penting dalam babad prambanan adalah sebagai berikut:
1. Silsilah kerajaan Pengging

2. Asal usul kerajaan Prambanan serta silsilah raja dan keluarganya

3. Perang akibat sayembara

4. Penolakan Rara Jonggrang terhadap Bandung Bandawasa

5. Rara Jonggrang melarikan diri dan meninggal di kali Opak

6. Bandung Bandawasa mengejar Rara Jonggrang

7. Kekalah Kerajaan Pengging oleh Dewatacengkar

8. Kedatangan Ajisaka yang akhirnya menjadi raja di Mendhangkamulan

\section{b. Novel Java Joe: Rahasia Bangkitnya Rara Jonggrang}

Novel Java Joe: Rahasia Kebangkitan Rara Jonggrang adalah satu novel populer yang menggunakan bahasa sehari-hari dikombinasi dengan istilah ilmu pengetahuan dan teknologi atau dalam istilah lain disebut science sebagai bentuk kreasi baru dari Babad Prambanan.

Novel ini memberikan suasana baru dengan menghadirkan cerita klasik sebagai pusat cerita yang dipadukan dengan unsur modern seperti penggunaan setting dan waktu yang lebih kekinian. Novel ini merupakan cerita berbingkai yang mengisahkan cerita di balik cerita yakni legenda Rara Jonggrang dibalik Kehidupan masyarakat modern yang dihubungkan dengan benang merahnya pemanfaatan energi alami dalam teknologi 
yang serba canggih.

Tema cerita dalam novel ini sebenarnya adalah perpaduan kehidupan masa lalu dengan masa modern.

\section{c. Novel Java Joe: Rahasia Bangkitnya Rara} Jonggrang sebagai pengekalan sekaligus penyangkalan Babad Prambanan sebuah kajian pengaruh

Resepsi adalah reaksi pembaca terhadap sebuah teks (Luxemburg. 1992: 79). Oleh pembaca teks itu dikonkretkan, dijadikan sebuah teks seperti dihayati dan difahami. Beberapa bentuk resepsi pembaca yang menanggapi sebuah teks karya sastra adalah resepsi produktif, yaitu mengambil unsurunsur dalam karya sastra terdahulunya diolah dalam sebuah karya sastra baru.

Seorang pengarang pada awalnya adalah seorang pembaca yang aktif dan produktif sehingga dia berusaha menjawab pertanyaan tentang apa sebenarnya yang ingin disampaikan oleh karya sebelumnya.

Kajian pengaruh bermula pada kajian mengenai asal usul suatu karya dan kajian ini harus berpegang pada pengetahuan dan penafsiran dari komponen -komponen yang menyangkut asal ususl karya tersebut (Guillen dalam Kasim, 1996: 45).

Dalam perbandingan Babad Prambanan dengan novel Java Joe: rahasia Kebangkitan Rara Jonggrang terdapat pengekalan cerita sekaligus penyangkalan cerita terkait keberadaan tokoh Rara Jonggrang. Pada analisis ini, Babad Prambanan merupakan membawa pengaruh terhadap Novel Java Joe: rahasia Kebangkitan Rara Jonggrang. Pengekalan dalam hal ini dibuktikan dengan adanya persamaan cerita sedangkan bentuk penyangkalan dibuktikan dengan adanya perbedaan cerita antara Babad dengan novel.

Kajian pengaruh dalam studi sastra bandingan suatu karya sastra ataupun genre yang dipengaruhi tentunya tidak seluruhnya sama dengan karya yang mempengaruhinya (Kasim, 1996: 40).

Hal yang sama terdapat pada novel Java Joe: Rahasia Kebangkitan Rara Jonggrang tentang adanya unsur dipengaruhi oleh Babad Prambanan yang berujung pada sebuah pengukuhan cerita yang terwujud dalam persamaan cerita antara karya yang lahir lebih awal kepada karya selanjutnya.

\section{d. Persamaan sebagai bentuk pengekalan}

Lebih jelasnya ditemukan beberapa persamaan cerita antara Babad Prambanan dengan novel Java Joe: Rahasia Bangkitnya Rara Jonggrang sebagai bentuk pengekalan. Dibuktikan dengan uraian berikut.

1) Rara Jonggrang tidak mau meninggalkan prambanan walau kerajaannya telah hancur 
Baik dalam babad maupun dalam novel dikisahkan bahwa setelah kekalahan negaranya, Rara Jonggrang tetap bertahan di kerjaannya walaupun telah hancur dan dikuasai oleh pihak musuh. Dia tidak mau meninggalkan tanah leluhurya. Sebagai bukti pada kutipan berikut:

\section{Dalam Babad Prambanan:}

Kematian Prabu Baka makin menimbulkan ketakutan orang-orang Prambanan. Putera Baeksi yang bernama Jaka Burdan sudah lama menaruh hati kepada rara Jonggrang, tetapi selama itu perasaan rindu asmara tersebut masih dipendam dalam hati saja. Pada sat kritis itu Jaka Burdan menyarankan kepada Rara Jonggrang untuk meningglakan Prambanan dan ia bersedia menjadi penunjuk jalan. Tetapi Rara Jonggrang tidak mau mengikuti saran Jaka Burdan karena Rara Jonggrang bersedia mati membela Prambanan Sugiarti, 1981: 33).

Dalam novel:

Menjelang ajal ayahandanya putus dalam satu gebrakan terakhir, ia menangkap sorot mata Prabu Baka menitahnya untuk lari pergi dari kancah pertempuran. Tapi ia tidak ingin bernjak, sampai nyawa ayahnya dijemput para leluhur, ia tetap tidak bergerak (Setiawan,2008: 5).

\section{2) Pertempuran yang terjadi dimenangkan oleh kerajaan Pengging}

Baik dalam babad maupun novel dikisahkan tentang terjadinya perang yang tidak berkesudahan antara kerajaan Pengging yang dipimpin Raden Bandung Bandawasa rajanya Prabu Darmamaya dengan Kerajaan Prambanan yang dipimpin Prabu Baka.

Keduanya mengisahkan bahwa pada peperangan tersebut dimenangkan oleh kerajaan Pengging. Dengan bukti berikut:

\section{Dalam Babad Prambanan:}

Pagi harinya para prajurit prambanan sudah mengikati senjatanya pergi meninggalkan Prambanan yang sudah tidak mngkin dipertahankan lagi. Berita kepergian prajurit Prambanan itu telah samai ke Raden bndung Bndawasa. Ia segera memrinytahkan prajurit pengging untuk memamsuki kota Prambanan yang telah ditinggalkan pergi oleh [para prajuritnya. Semua harta benda prambanan telah dan dikumpulkan menjadi satu (Sugiarti, 1981: 33).

Dalam novel:

Dari korban-korban yang bergelimpangan dan puing-puing yang berserakan di segala penjuru, orang bisa tahu perang mahabesar baru saja lewat. Keraton Baka lulh lantak rata dengan tanah. Umbulumbul kerajaan Pengging yang berkibar di antara puing menandakan siapa pemenangnya. 


\section{3) Pembunuh Prabu Baka adalah Raden} Bandung Bandawasa

Dikisahkan pada peperangan yang terjadi antara kerjaan Pengging dengan Prambanan Raden Bandung Bandawasalah yang mampu mengalahkan Prabu Baka. Keduanya menyebutkan kesaktian Raden Bandung Bandawasa yang sangat tinggi. seperti kutipan berikut:

\section{Dalam Babad Prambanan:}

Berita kematian tumenggung Bandawasa dan kekalahan prajurit Prambanan menimbulkan kemarahan sang Prabu Baka. Ia segera turun ke medan pernag berhadapan langsung dengan dengan Raden Bandung Bandawasa. Prajurit bantuan dari Prambanan okut maju pula di belakang rajanya. Amukan Prabu Baka menimbulkan korban prajurit Pengging yang tidak sedikit pula. Raden Bandung pun mulai berhadapan langsung dengan Prabu Baka. Mereka saling memeukulnamun kedanya tidak ada yang terkalahkan. Lama-kelamaan gada Prabu Baka dapat direbut oleh Raden Bandung Bandawasa dan Prabu Baka jatuh tertelungkup lalu ditendang kepalanya menyebabkan tewasnya Prabu Baka (Sugiarti, 1981: 32).

Dalam novel:

Gema pertarungan puncak antara dirinya dan Prabu Baka masih mengganggu benaknya. Bahkan darah hangat Sang Prabu dibiarkan mengering di telapakya. Ini adalah pertarungan paling dahsyat yang pernah dilaganya. Hampir semua jurus andalannya telah dikerahkan,dan itu pun masih sulit membuat Prabu Baka bertekuk lutut. Hanya berkat tekad dan kemurnian tenaga muda yang dimilikinya, Prabu Baka yang sepuh akhirnya dapat ditaklukkan olehnya. Dialah Pangeran muda Pengging, Bandung Bandawasa (Setiawan, 2008: 3).

\section{4) Bandung Bandawasa adalah putera} mahkota Kerajaan Pengging

Dalam konteks asal usul pangeran Bandung Bandawasa dalam babad prambananan maupun novel mempunyai persamaan yakni Pangeran Bandung Bandawasa adalah putra mahkota Kerajaan Pengging yang berhasil menaklukkan kerajaan Prambanan.

\section{Dalam Babad Prambanan:}

Raden Darmamaya sedang menikmati kebahagiaan bersama istrinya, Dewi Larasati dari Pengging. Mereka hidup bahagia karena keduanya saling memberi dan menerima. Selang beberapa waktu kemudian Dewi Larasati hamil. Ketika tiba saat melahirkan ternyata ia melahirkan seorang putra laki-laki, berwajah bagus dan perkasa seperti Raden Gatutkaca dari Pringgandani. Anak tersebut diberi nama Raden Bandung (Sugiarti, 1981: 21). 
Dalam novel Java Joe: Rahasia Bangkitnya Rara Jonggrang:

Sampai akhirnya datanglah Bandung Bandawasa membawa pasukan lengkap menantang perang tanding. Kedatangannya merupakan jawaban setelah niat baik utusan Pengging dipermalukan karena sama sekali tidak dihiraukan.

"Dinda Ayu Rara Jonggrang, ikutlah denganku, Bandung Bandawasa, Pangeran Muda Kerajaan Pengging. Kau akan kusunting jadi pendampingku, bukan selir. Ayahanda Prabu pasti berkenan bermantukan Dinda. Akan kupersiapkan pesta empat puluh hari empat puluh malam bila Dinda berkenan" ( Setiawan, 2008: 7).

\section{5) Bandung Bandawasa jatuh cinta kepada}

Rara Jonggrang karena kecantikannya dan berniat memperisteri putri Rara Jonggrang.

Masing-masing cerita mempunyai cara tersendiri dalam menggambarakan kecantikan Rara Jonggrang yang memikat hati Bandung sehingga jatuh cinta pada sang putri. Namun esensi dari kedua cerita tersebut sama. Terlihat dalam kutipan berikut:

\section{Dalam Babad Prambanan:}

Ketika memasuki keraton Prambanan, Raden Bandung Bandawasa tersirap darahnya melihat kecantikan Rara Jonggrang seorang diri, ia jatuh cinta kepada Rara Jonggrang arena wanita itu mempunyai bentuk tubuh seperti laki-laki yang sudah lama diharapharapkan oleh Bandung Bandawasa (Sugiarti, 1981: 31)

Wajah dan tingkah laku Rara Jonggrang sangat menarik hati Raden Bandung Bandawasa. Ketika ia ditanyai oleh Raden Bandung Bandawasa, Rara Jonggrang menceritakan bahwa dirinya adalah adik Prabu Karungkala yang telah tewas dalam peperangan. Ia masih perawan dan tidak mau kawin. Raden Bandung Bandawasa terus langsung menyatakan ingin memperisteri Rara Jonggrang. Dengan mengucapkan terimakasih Rara Jonggrang tidak bersedia menerima kehendak Bandung Bandawasa karena dirinya belum ingin kawin (Sugiarti, 1981: 34).

Dalam novel:

Sejak upacara Ciwa dulu, hanya satu putri diantara puluhan sekar kedaton yang memikat hatinya. Ada sesuatu pada senyum bibir indah Rara Jonggrang yang sangat menggugah rindunya. Merasuk ke dalam setiap mimpinya.

Bahwa putri Baka memiliki bibir nan indah memang terkenal sampai mancanegari. Setiap pangeran merindukan untuk menikahinya. Dan itu bukan bualan semata, terlebih setelah Bandung benar-benar mendapat sunggingan senyum bibir nan indah rupawan itu. Bandung 
semakin tergila-gila (Setiawan, 2008: $10)$.

\section{6) Rara Joggrang menolak Bandung} Bandawasa dengan cara membuat siasat.

Kedua cerita menggambarkan penolakan Rara Jonggrang terhadap Bandung Bandawasa. Karena merasa terancam maka Rara Jonggrang berusaha mencari jalan untuk dapat menghindari pinangan Bandung Bandawasa. Terlihat dalam penggalan cerita berikut:

\section{Dalam Babad Prambanan:}

Ketika hari mulai senja Raden Bandung Bandawasa tidak tahan lagi menahan kobaran asmaranya. Ia memutuskan akan memaksa Rara Jonggrang untuk mau menerima kehendaknya. Karena merasa terdesak Rara Jonggrang mengatakan kalau memang Raden Bandung Bandawasa benar-benar cinta kepadanya maka Rara Jonggrang ingin minta sesuatu. Permintaan apapun akan disanggupi oleh Raden Bandung Bandawasa. Rara Jonggrang mengatakan bahwa dirinya tidak minta mas intan tetapi sesuai dengan harapan almarhum ayahnya Resi Suwarda, maka Rara Jonggrang hanya minta candhi batu seribu yang harus dapat diselesaikan dalam satu malam. Rara Jonggrang mohon agar Radeb Bandung Bandawasa dapat mewujudkan permintaannya itu. Apabila yang diminta Rara Jonggrang dapat terkabulkan maka ia bersedia diperistri oleh Raden Bandung Bandawasa. Sedangkan kalau permintaannya itu tidak dapat terkabulkan maka ia tetap tidak mau diperistri dan bersedia untuk bunuh diri dalam mempertahankan dirinya (Sugiarti, 1981: 34).

Dalam novel:

Lama Rara Jonggrang mengulur waktu. Tapi waktunya kini tinggal di ujung kecap. Setelah waktu berkabungnya usai, ketika Bandung memanggilnya untuk sowan, sejak itu waktunya telah menjadi milik Bandung, sang penakluk.

“ Gusti Pangeran Bandung Bandawasa, hanya satu pinta hamba, bangunlah seribu candi di tanah ini. Tanah kelahiran hamba, tanah tempat abu Ayahanda menyatu bumi. Seribu saja. Tidak lebih tidak kurang. Agar darma bakti hamba ke Ayahanda mencapai Swarga loka. Dan Dewa Surya besok pagi dapat tersenyum menyinari maha Gusti Pangeran. Mengiringi langkah hamba meninggalkan kaputren ( Setiawan, 2008: 11-12).

\section{7) Pada saat membuat candi, Bandung Bandawasa dibantu oleh kekuatan gaib.}

Pada cerita babad terdapat perbedaan pelaku yang membantu Bandung Bandawasa, akan tetapi keduanya samasama mengisahkan tentang bantuan pihak lain dalam usaha membuat candi yang dilakukan oleh Bandung Bandawasa. Seperti 
pada kutipan berikut:

Dalam Babad Prambanan :

Raden Bandung Bandawasa segera memerintahkan prajuritnya untuk menjaga rara Jonggrang dalam keraton. Raden Bandung Bandawasa kemudian pergi. Di luar istana ia mohon kepada Dewata agar diberi pertolongan untuk mengabulkan permintaan Rara Jonggrang dalam membuat candi batu seribu dalam tempo satu malam.

Pada hari selasa Kliwon ketika telah larut malam Raden Bandung Bandawasa mulai mengangkati batubatu untuk embuat candi seribu. Atas pertolongan dewata arca candi seribu pun hampir selesai ketika hari mulai fajar (Sugiarti, 1981: 35).

Dalam Novel:

Halilintar menyambar-nyambar. Bumi bergetar hebat.

Ajian ini memang hebat. Pada dasarnya jin takluk terhadap manusia. Barang siapa yang dapat menguasai kunci langit, dia dapat menguasai semua raja jin di kolong jagad. Ajian Bhrekasa adalah salah satu kunci langit itu. Ajian ini sangat jarang dipakai orang karena memang hanya sedikit orang yang mampu menguasainya. Apalagi total seperti yang digelar Bandung Bandawasa.

Dia atas bukit, Bandung Bandawasa berkacak pinggang mengagumi kehebatannya. Bahkan penguasa alam seberangpun takluk padanya. Satu demi satu arca dan candi berdiri silih berganti. Sembilan ratus sembilan puluh sembilan (Setiawan, 2008: 13-15).

\section{e. Perbedaan cerita sebagai wujud penyangkalan}

Pada analisis perbedaan ini terdapat beberapa kategori yang didasarkan pada cerita yang ada pada masing-masing objek. Sebagai berikut:

\section{1) Terkait hubungan Rara Jonggrang dengan Pangeran Baka}

Dalam Babad Prambanan Rara Jonggrang dikisahkan sebagai adik Prabu Karungkala. Hubungannya dengan Raden Baka adalah sebagai kekasih. Sedangkan dalam Novel tersebut Rara Jonggrang adalah Putri Raden Baka.

Pada Babad Prambanan, disebutkan bahwa Pangeran Baka atau Raden Baka adalah Kekasih Rara Jonggrang. Raden Baka tidak berasal dari kerajaan Prambanan melainkan dari kerajaan Salembi dan masih mempunyai hubungan persaudaraan dengan Pangeran Bandung Bandawasa yakni paman Pangeran Bandung karena ayahnya adalah kakak Prabu Angklingdriya. Seperti kutipan berikut. 
Alkisah ketika mereka sedang bersitegang itu tiba-tiba datanglah Resi Basukeli dari Prambanan ke tempat pertapaan Raden Baka. Setelah berbasa-basi sejenak kemudian Resi BAsukeli menerangkan bahwa ia datang dari Prambanan diutus oleh RAra Jonggrang untuk mencari seorang jago perang untuk menghadapi Pengging. Mereka yang dapat memukul mundur Pengging akan mendapat hadiah untuk mempersunting Dewi Rara Jonggrang dan sekaligus dinobatkan sebagai raja Prambanan (Sugiarti,1981: 24-25).

\section{2) Nasib Rara Jonggrang setelah siasatnya terbongkar Bandung Bandawasa}

Terjadi juga perbedaan akhir cerita kematian Rara Jonggrang. Dalam Babad Prambanan, Rara Jonggrang tidak dikutuk oleh Bandung Bandawasa, melainkan melarikan diri dan tidak ditemukan sampai dia diceritakan hanyut di kali Opak setelah melahirkan putrinya bernama Rara Temon, hasil hubungannya dengan Raden Baka. Sedangkan dalam novel, Rara Jonggrang dikutuk oleh Bandung Bandawasa karena kesal telah dikelabui oleh Rara Jonggrang.

Sedangkandalamnovel dikisahkan bahwa Jasad Rara Jonggrang diselamatkan oleh Gandrung Wicaksana dan disembungyiakan di sebuah tempat rahasia dan akan bangun pada saat purnama perak.

\section{3) Munculnya tokoh Gandrung Wicaksono}

Penyangkalan utama novel terhadap babad adalah dimunculkannya tokoh Gandrung Wicaksono pada novel padahal dalam Babad Prambanan tidak disebut sama sekali.

Dalam novel dikisahkan bahwa Gandrung adalah adik Bandung Bandawasa satu ayah tetapi berlainan ibu. Dia juga merupakan putra mahkota dari permaisuri lain.

Dengan demikian hal itu merupakan kreasi dari pengarang baru sebagai sebuah versi cerita baru. Dalam tema cerita, novel ini mengangkat sesuatu yang baru yang dapat dikategorikan sebagai jawaban Babad Prambanan terkait dengan kekasih Rara Jonggrang.

\section{f. Reaksi sebagai pergeseran nilai pada} Novel Java Joe: Rahasia Bangkitnya Rara Jonggrang terhadap Babad Prambanan sebuah versi cerita

Resepsi karya sastra tidak hanya oleh para pembaca yang sezamannya dengan penulis, tetapi juga resepsi oleh angkatan pembaca yang berturut -turut sesudah masa penciptaannya. Karya sastra dibaca, dimainkan, dinikmati, dinilai dan ikut menentukan nilai dan kriteria sastra serta horizon harapan pembaca dan penikmat karya sastra.

Pertanyaan yang muncul kemudian 
adalah sampai dimana dan untuk golongan apa kritik sastra klasik dapat dianggap masih relevan? Dalam penelitian sastra yang melibatkan karya sastra tradisional terdapat sarana lain untuk menelusuri resepsi yaitu lewat variasi naskah, versi-versi baru sebuah teks lama, dalam bentuk saduran, terjemahan dan lain-lain (Teeuw, 1984: 328).

Sebagaimana semangat zaman Jauss, masing-masing generais mempunyai pembacaan yang berbeda dengan generasi sebelum maupun sesudahnya. Dimunculkannya tokoh Gandrung Wicaksana merupakan jawaban kunci alasan penolakan Rara Jonggrang terhadap Bandung Bandawasa yang tidak ditemukan dalam Babad Prambanan merupakan pemenuhan horizon harapan yang masih terbuka dan kosong dalam Babad Prambanan yang masih dapat diisi oleh pembacaan berikutnya dalam hal ini diwakili oleh Novel Java Joe : Rahasia Kebangkitan Rara Jonggrang yangdapat disebut sebagai versi lain cerita Rara Jonggrang yang berbeda dengan Babad Prambanan.

\section{Simpulan}

Dari analisis di atas dapat disimpulkan bahwa kehadiran Novel Berjudul Java Joe: Rahasia Kebangkitan Rara Jonggrang karya J.H Setiawan adalah perspektif baru yang merupakan tanggapan dari Babad

\section{Prambanan.}

Novel Java Joe: Rahasia bangkitnya Rara Jonggrang merupakan tanggapan karya sebelumnya yang berupa babad dengan menghadirkan ide baru dan mempergunakan kreasi-kreasi berbalut science sebagai tampilan baru. Tanggapan tersebut merupakan penyangkalan cerita yang telah ada tentang cerita masa lampau sehingga esensi cerita yang ada tidak diabaikan. Perbedaan ide tersebut semata-mata adalah hasil pembacaan yang bertujuan memenuhi horizon harapan yang masih kosong pada karya sastra sebelumnya yang dijadikan sumber. Bisa jadi novel tersebut merupakan koreksi terhadap ide cerita pada karya sastra sebelumnya. 


\section{Daftar Pustaka}

Jauss, H.R. 1982. Toward an Aesthetic of Reception. Minneapolis: University of Minnesota Press.

Kasim, Razali. 1996. Sastra Bandingan ruang lingkup dan metode. Medan: Universitas Sumatera Utara Press.

Luxemburg, Jan Van, Dick Hartoko (penerj). 1992. Pengantar Ilmu Sastra. Jakarta: Gramedia Pustaka Utama.

Panuti , Sudjiman. 2006. Kamus Istilah Sastra. Jakarta: UI Press.

Pradopo, Rachmat Djoko. 2008. Beberapa Teori Sastra, Metode Kritik, dan Penerapannya. Yogyakarta: Pustaka Pelajar.

Program Studi Sastra Indonesia dan Jawa. 1996. "Sejarah Sastra sebagai Tantangan” sebuah makalah. Yogyakarta: UGM.

Robson, S.O, Gunawan, Kentjanawati (penerj). 1994. Prinsip-prinsip Filologi Indonesia. Jakarta: Pusat Pembinaan dan pengembangan Bahasa dan Universitas Leiden.

Sugiarti, Srima dan Aditrijono, dkk. 1981. Babad Prambanan. Jakarta: Depdikbud, Proyek Penerbitan Buku Sastra dan Daerah.

Setiawan, J.H. 2008. Java Joe: Rahasia Kebangkitan Rara Jonggrang. Yogyakarta: Bentang Pustaka.

Teeuw, A. 1984. Sastra dan Ilmu Sastra. Jakarta: Dunia Pustaka Jaya. 